\title{
Hydrogen absorption in carbon allotropes and talc
}

\author{
J. Cermak ${ }^{1,2 *}$, L. $\mathrm{Kral}^{1}$ \\ ${ }^{1}$ Institute of Physics of Materials, AS CR, v.v.i., Zizkova 22, CZ-61662 Brno, Czech Republic, \\ ${ }^{2}$ CEITEC-Institute of Physics of Materials, AS CR, v.v.i., Zizkova 22, CZ-61662 Brno, Czech Republic
}

Received 24 November 2017, received in revised form 12 March 2018, accepted 13 March 2018

\begin{abstract}
Carbon is frequently used as an additive that facilitates fine ball-milling of hydrogen storage (HS) alloys. It is commonly supposed that the carbon does not take part significantly in HS above the room temperature. In the present paper, hydrogen sorption in three carbon allotropes (carbon black, graphite and modified carbon nano-plates) and in magnesium silicate monohydrate (talc) was studied in temperature interval from 423 to $623 \mathrm{~K}$. HS capacity from about 0.4 wt. $\% \mathrm{H}_{2}$ (talc) to about $1.1 \mathrm{wt} . \% \mathrm{H}_{2}$ (carbon black) was observed at a hydrogen pressure of 25 bar. The HS in all the studied materials was very weakly temperature activated.
\end{abstract}

K e y w or d s: hydrogen absorption, hydrogen storage, ball milling, carbon

\section{Introduction}

Effective hydrogen storage (HS) in solid phase reservoirs is one of the key problems of hydrogen power industry. Although a large variety of new HS materials (HSM's) was studied in the last years [1, 2-12], Mg-based alloys are constantly in the focus of the interest of both basic and applied research $[13,14]$. The main reasons are: (i) low cost and abundance of $\mathrm{Mg}$ and the fact that it may be easily recycled from the waste $[15,16]$, (ii) low weight-to-storage-capacity ratio, (iii) cheap production of Mg-based HSM's, (iv) biocompatibility, and (v) these materials are usable repeatedly because the discharged HSM can be easily hydrogen-recharged simply by reversion of desorption. Last but not least, (vi) cycle stability of these HSM's is very good.

However, pure $\mathrm{Mg}$ is not suitable for HS because of the poor kinetics of absorption/desorption (A/D) cycle. Therefore, the $\mathrm{Mg}$ base is often alloyed with other elements [14], among others with carbon. The mechanism of carbon effect is, however, not fully understood as yet. Authors of ref. [17] observed the improvement of hydrogen absorption of $\mathrm{Mg}$ with $\mathrm{C}$ only, whereas almost no effect on hydrogen desorption was reported. Several possible mechanisms were proposed in the literature explaining the observed influence of carbon upon the sorption characteristics of $\mathrm{Mg}$ and
Mg-Ni alloys. Carbon is considered, first of all, to be an anti-sticking agent [18] that prevents agglomerating, bonding and mutual welding of ball-milled particles during the ball-milling. In this way, carbon is believed to facilitate the fine ball-milling and production of powder with smaller grain size. Authors of papers $[17,19]$ conclude that carbon imparts also enhanced resistance against oxidation to $\mathrm{Mg}$ alloys. It was found as well that carbon enhances the density of matrix defects, which may decrease the hydride decomposition temperature. Catalytic [20, 21] and beneficial synergy effects of carbon and other alloy components [18, 22] upon hydrogen desorption were also reported. A large number of dangling bonds of carbon generated during milling were identified as sites of easy hydrogen absorption in ref [20]. In [23], a saturation behaviour in carbon concentration was reported. The authors concluded that the addition of more than 9 wt. $\%$ of graphite to $\mathrm{Mg}-\mathrm{V}$ fine powder did not lead to any further acceleration of hydrogen absorption. The newest results are reported in studies [1, 24-26].

Compositions of HSM's with carbon nanofibres and nanoparticles were studied, e.g., in [27-31], HSM's containing porous carbon were investigated in [32, 33]. Carbon was also introduced in the form of various allotropes (graphene, carbon black, onion-like carbon) and the form of compounds formed from organic carbon precursors [34-40]. It is commonly accepted that

*Corresponding author: e-mail address: cermak@ipm.cz 


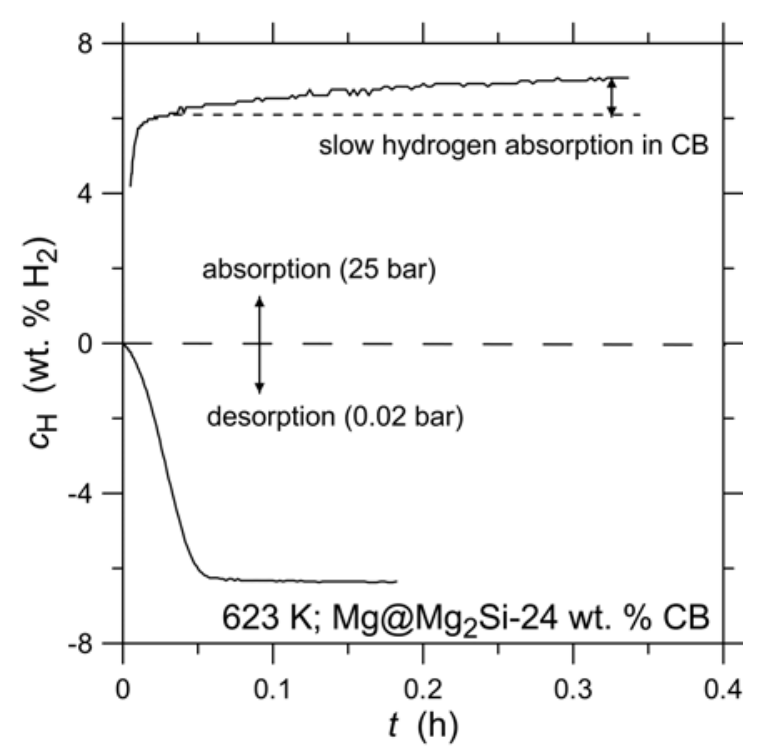

Fig. 1. Hydrogen sorption in $\mathrm{Mg} @ \mathrm{Mg}_{2} \mathrm{Si}-24 w t . \% \mathrm{CB}$ at $623 \mathrm{~K}$.

the considerable HS in these complex materials can be achieved at low temperatures. Top candidates are commercially attractive typically at cryogenic temperatures and at high pressures above 100 bars, which can be considered as an alternative to HS by hydrogen liquefaction [13].

In our pilot study of HS in a complex ball-milled composition consisting of $\mathrm{Mg}$ with $\mathrm{Mg}_{2} \mathrm{Si}$ catalyzing particles and with 24 wt.\% carbon black (CB), it was observed that slow hydrogen absorption followed after the rapid initial absorption period in samples containing CB. No similar behaviour was observed during desorption - see Fig. 1.

It could be speculated that hydrogen absorbed during the slow process was accommodated in particles of CB itself. This fraction of stored hydrogen, however, should be rapidly released before desorption regime was adjusted and started. To support this idea, HS in chosen pure carbon allotropes was investigated in this paper at non-cryogenic temperatures between 423 and $623 \mathrm{~K}$ and under hydrogen pressure up to 25 bars. The present study contributes to the sparse data published in the literature on HS in pure carbon. The measurement of HS in talc completes the picture, since talc does not contain carbon, but shows anti-sticking effect similar to that of carbon.

\section{Experimental}

The samples for hydrogen sorption experiments were in the form of fine powders. A sample of pure graphite $(\mathrm{G})$ was prepared from spectral electrodes with very weak spectral lines of $\mathrm{Al}, \mathrm{Fe}$ and $\mathrm{Si}$.

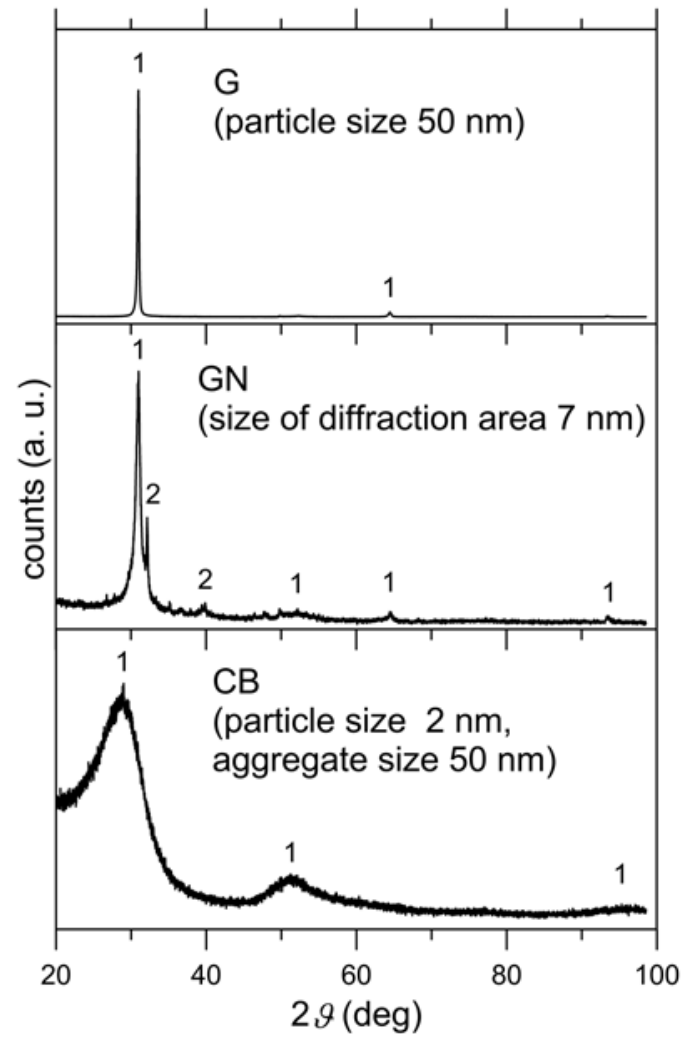

Fig. 2. XRD pattern of carbon samples. 1-carbon, 2-polycarboxylate groups.

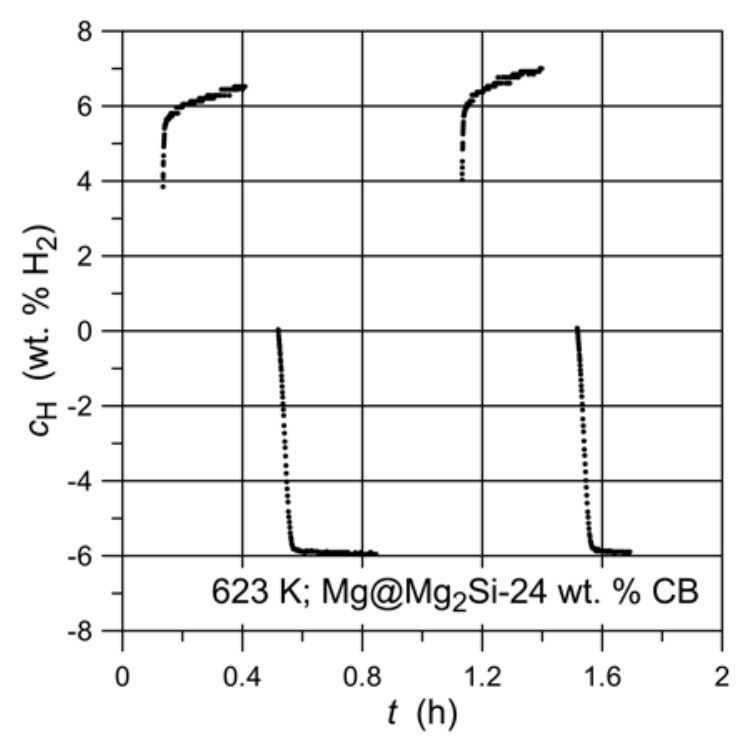

Fig. 3. Two subsequent hydrogen sorption cycles.

The original form - solid bar of $5 \mathrm{~mm}$ in diameter - was crushed in a mortar. Fine powder of CB with $\mathrm{O}_{2}<2$ wt. $\%, \mathrm{~S}<0.17$ wt. $\%$ was purchased from CABOT Switzerland GmbH and polycarboxylatefunctionalized graphene nanoplatelets (GN) from Sigma-Aldrich Chemie GmbH. Powdered talc (T) - 

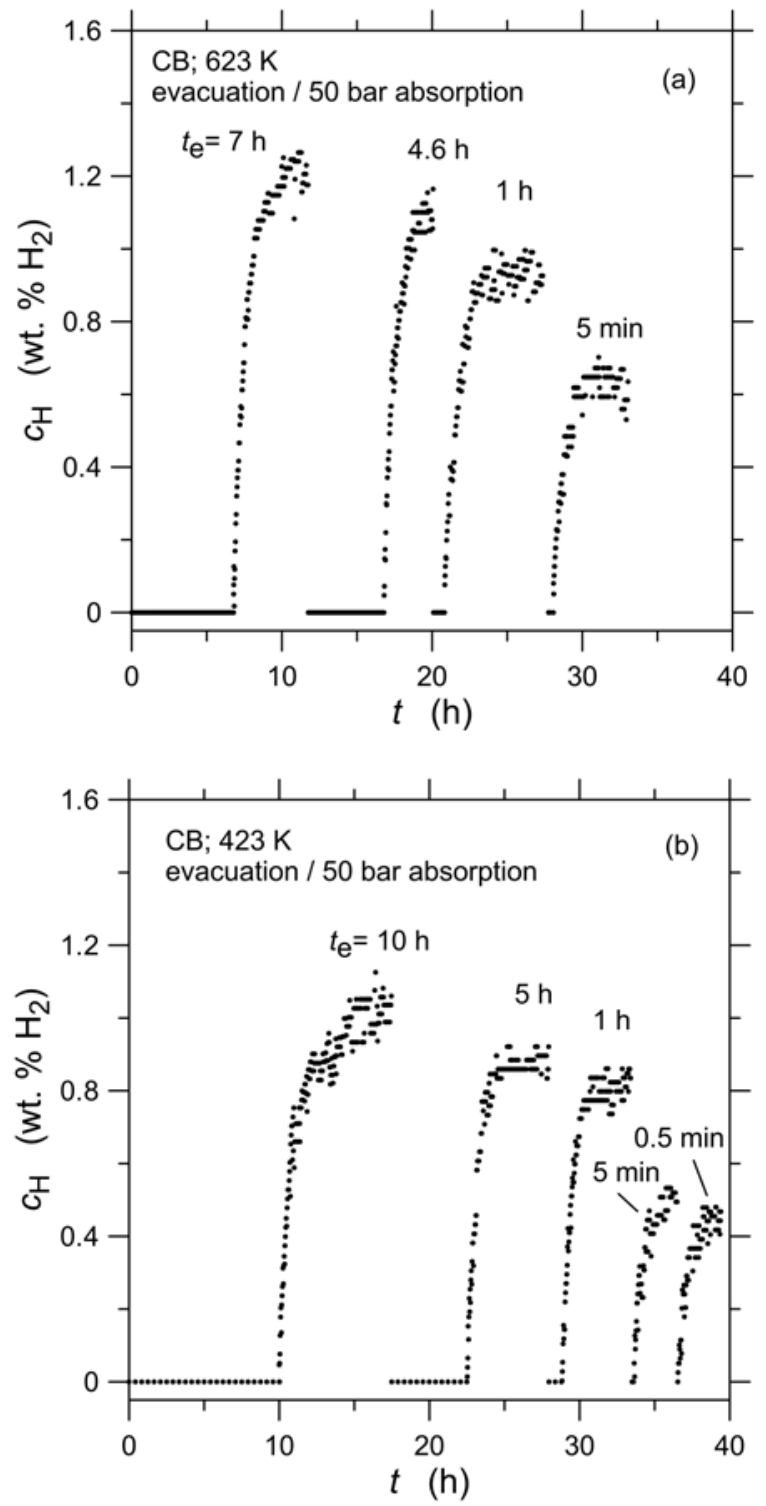

Fig. 4. Sorption sequence consisting of repeated evacuation for time $t_{\mathrm{e}}$ in the dynamic vacuum of $2 \times 10^{-3} \mathrm{mbar}$ followed by absorption in 50 bar at $623 \mathrm{~K}$ (a) and $423 \mathrm{~K}$ (b).

$3 \mathrm{MgO} \cdot 4 \mathrm{SiO}_{2} \cdot \mathrm{H}_{2} \mathrm{O}$ - was obtained from Alfa Aesar/ Thermo Fisher (Kandel) GmbH. Mean grain size of particles was obtained from XRD patterns with the help of the X'Pert Pro MPD device using CoK $\alpha$ radiation using the HighScore Plus SW and ICSD databases [41]. The mean size of aggregates (clusters of fine particles) and concentration of two main impurities $\left(\mathrm{O}_{2}\right.$ and $\left.\mathrm{S}\right)$ was estimated by SEM JEOL JSM 6460 equipped with the EDS/WDS Oxford Instruments analyzer. Hydrogen sorption experiments were carried out using Sieverts-type gas sorption analyzer PCT-Pro Setaram Instrumentation at temperatures between 423 and $653 \mathrm{~K}$ and under hydrogen pressure

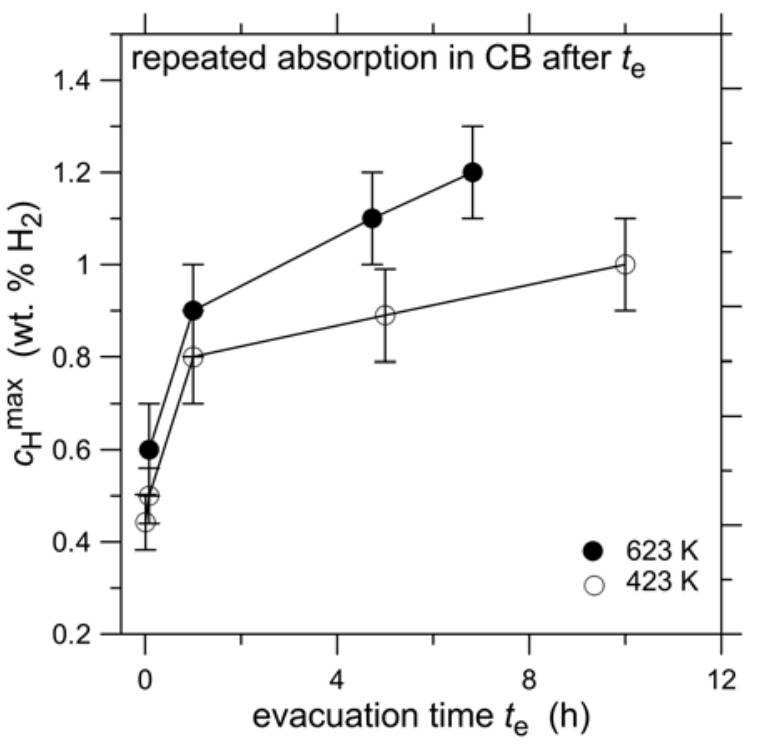

Fig. 5. Maximum HS capacity of CB after evacuation for time $t_{\mathrm{e}}$ followed by charging in $\mathrm{H}_{2}$ in 50 bars.

up to 25 bar. The purity of both hydrogen and helium (calibration gas) was $6 \mathrm{~N}$. The pilot measurement was carried out with the ball-milled alloy $\mathrm{Mg} @ \mathrm{Mg}_{2} \mathrm{Si}-24$ wt.\% CB prepared using milled Si $(6 \mathrm{~N})$.

\section{Results and discussion}

The grain size of powders, obtained by XRD and SEM, is obvious from Fig. 2.

$\mathrm{X}$-ray analysis confirmed the presence of carbon phase only. In case of GN, also peaks from polycarboxylate groups appeared. The carbon peaks obtained for CB are slightly shifted to lower values of $\vartheta$ due to the amorphous structure. The size of carbon particles in $\mathrm{G}$ and $\mathrm{CB}$ and size of diffraction area in GN was obtained using the Rietveld analysis from the width of related carbon peaks.

It is illustrated in Fig. 1 that the absorption branch always showed a slow component that was absent during the hydrogen desorption. This is also documented in Fig. 3, where the detail of sorption cycling (two subsequent cycles in real time) is shown. It is also clear from Fig. 3 that there is a certain time interval between the absorption and the next desorption (several minutes) needed to swap the sorption regimes of the apparatus. During this time interval, the sample chamber was evacuated to ultimate pumping pressure of about $2 \times 10^{-3}$ mbar until the registration of hydrogen desorbed into the chosen fixed volume starts.

To quantify the extent and kinetics of hydrogen desorption during the evacuation, a cyclic sorption sequence was investigated consisting of evacuation in a dynamic vacuum $\left(2 \times 10^{-3} \mathrm{mbar}\right)$ followed by hy- 

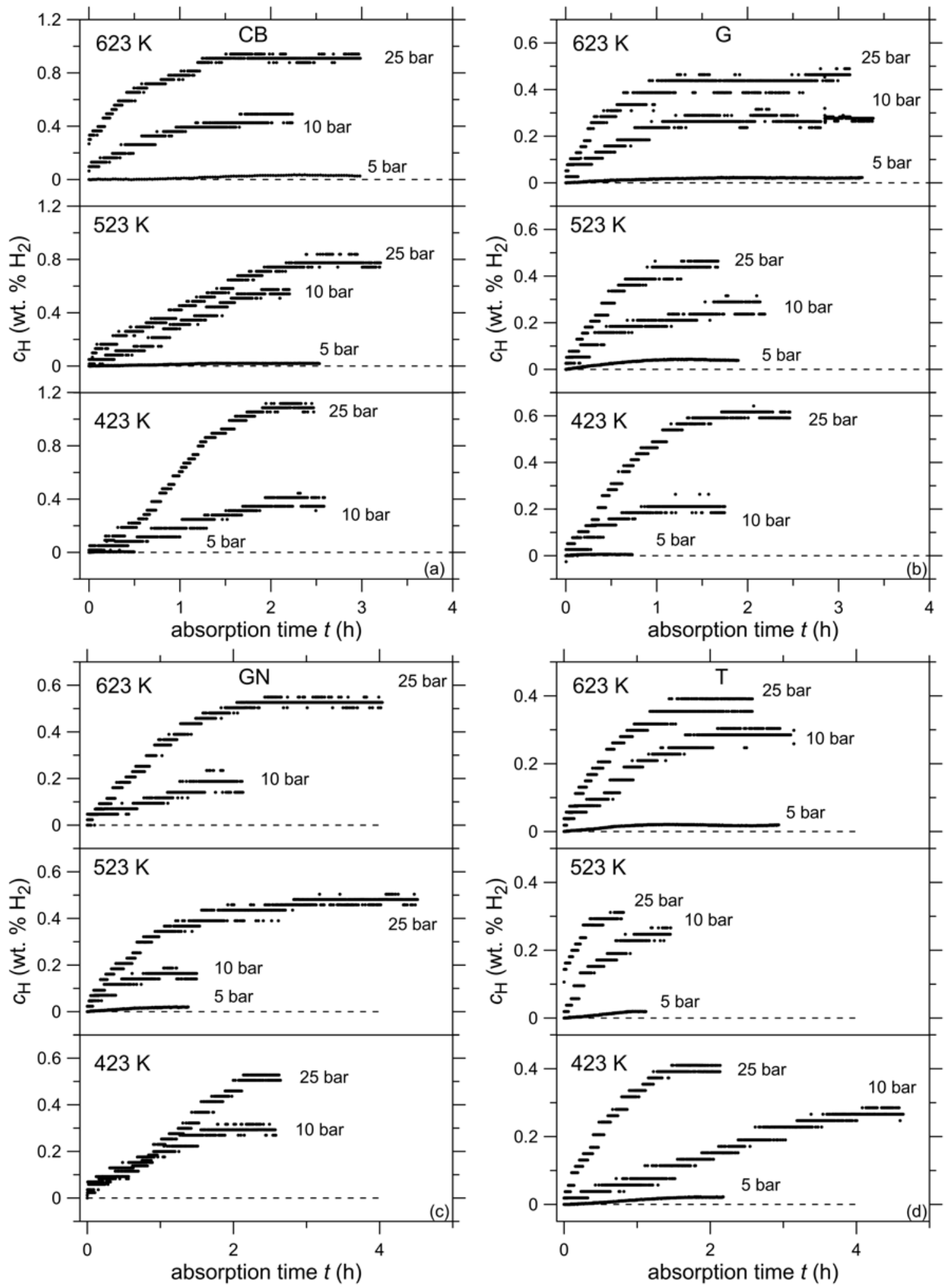

Fig. 6. Hydrogen uptake in samples CB (a), G (b), GN (c), and T (d).

drogen absorption at 50 bars. Time of evacuation, $t_{\mathrm{e}}$, was varied from several hours down to about $5 \mathrm{~min}$. Results in Fig. 4a show that thoroughly evacuated sample $\mathrm{CB}$ (evacuated for $7 \mathrm{~h}$ at $623 \mathrm{~K}$ ) could absorb about 1.2 wt.\% $\mathrm{H}_{2}$, whereas hydrogen fully charged sample evacuated for a short time of $5 \mathrm{~min}$, took up about one half of the amount. An experiment conducted at $423 \mathrm{~K}$ led to similar results with the only 
difference that the ultimate hydrogen concentration $c_{\mathrm{H}}^{\max }$ in the fully charged sample was somewhat lower (Fig. 4b). Hence, it can be seen that the CB has lost about one half of $c_{\mathrm{H}}^{\max }$ even during the first several tens of seconds of evacuation.

Dependence of HS capacity of CB at 623 and $423 \mathrm{~K}$ measured in a dynamic vacuum of $2 \times 10^{-3}$ mbar on evacuation time $t_{\mathrm{e}}$ is plotted in Fig. 5 .

The error bars cover the scatter of $c_{\mathrm{H}}^{\mathrm{max}}$ from Fig. 4 . The results explain the asymmetry of cycling curves observed in our pilot experiment (see examples in Figs. 1, 3) since they show that considerable amount of hydrogen can be desorbed relatively quickly during early stages of evacuation. It can be concluded that $\mathrm{CB}$ added to HS materials contributes to overall HS capacity and that a considerable fraction of hydrogen (about one half of total absorbed hydrogen) can be desorbed very quickly. Hydrogen uptake in thoroughly desorbed samples CB, G, GN and T was measured at pressure 5, 10 and 25 bars at temperatures 423, 523 and $623 \mathrm{~K}$. Results are presented in Figs. 6a-d.

The absence of curves $c_{\mathrm{H}}(t)$ for pressure 5 bars in diagrams in Fig. 6 means that the hydrogen uptake was below the detection limit of the pressure detector. It can be seen that maximum value $c_{\mathrm{H}}^{\max }$ of hydrogen absorption was lowest for $\mathrm{T}$ the highest in $\mathrm{CB}$. For all investigated materials, $c_{\mathrm{H}}^{\max }$ was typically reached in about $2 \mathrm{~h}$. It was found that $c_{\mathrm{H}}^{\max }$ depended significantly on hydrogen pressure, but temperature dependence of $c_{\mathrm{H}}^{\max }$, on the other hand, was not significant. This enabled to relinquish totally the temperature dependence in the temperature interval investigated and present $c_{\mathrm{H}}^{\max }$ as a function of hydrogen pressure only see in Fig. 7. The shaded area covers values obtained irrespective of the absorption temperature. Its width is given by scattering of individual values of $c_{\mathrm{H}}^{\max }$ (see Fig. 6).

\section{Summary}

It was found that all studied materials can absorb hydrogen in the temperature range from 423 to $623 \mathrm{~K}$ and that hydrogen sorption behaviour was dependent on hydrogen pressure. No significant temperature dependence of sorption behaviour was found in the temperature interval $423-623 \mathrm{~K}$. Comparing the studied materials, it was observed that $\mathrm{HS}$ capacity $c_{\mathrm{H}}^{\max }$ at 25 bars of hydrogen varied between about 0.4 wt. $\% \mathrm{H}_{2}$ (for $\mathrm{T}$ ) to about $1.1 \mathrm{wt} . \% \mathrm{H}_{2}$ (for CB). Typical absorption time $t_{\mathrm{e}}$ needed to approach the $c_{\mathrm{H}}^{\max }$ is about 1 to $2 \mathrm{~h}$. About one half of the total absorbed hydrogen is desorbed in a short time of approximately one min. $\mathrm{CB}$ showed the maximum value of $c_{\mathrm{H}}^{\max }$ and, therefore, it is the best component of HSM's; hydrogen sorption behaviour of $\mathrm{CB}$ can significantly contribute to $\mathrm{HS}$ properties in CB-containing HSM's. The results can

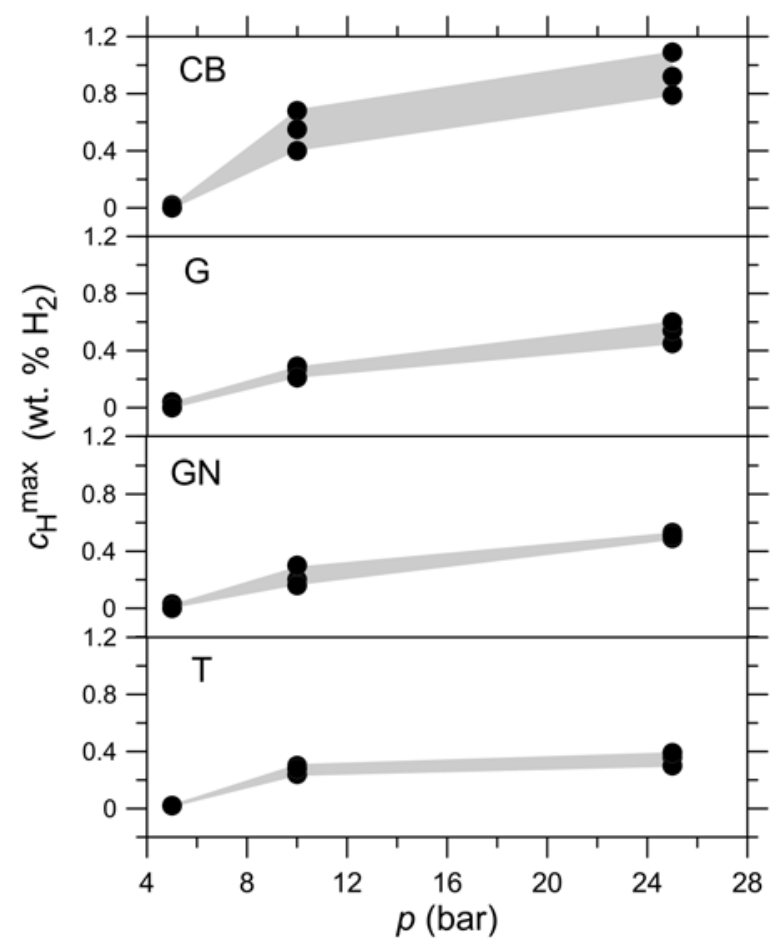

Fig. 7. Pressure dependence of maximum hydrogen uptake in samples $\mathrm{CB}, \mathrm{G}, \mathrm{CN}$ and $\mathrm{T}$ in temperature interval $423-$ $623 \mathrm{~K}$.

explain asymmetry of cyclic sorption curves observed by common technique (using, e.g., the Sieverts-type gas sorption analyzer PCT-Pro Setaram Instrumentation) in our pilot experiment with $\mathrm{Mg} @ \mathrm{Mg}_{2} \mathrm{Si}-\mathrm{CB}$.

\section{Acknowledgements}

This work was supported by The Czech Science Foundation - Project No. GACR 17-21683S. The authors would like to express their thanks to Dipl. Eng. P. Roupcova for XRD measurements.

\section{References}

[1] Yu, X., Tang, Z., Sun, D., Ouyang, L. Z., Zhu, M.: Prog. Mater. Sci., 88, 2017, p. 1. doi:10.1016/j.pmatsci.2017.03.001

[2] Cermak, J., Kral, L., Roupcova, P.: Kovove Mater., 54, 2016, p. 389. doi:10.4149/km_2016_6_389

[3] Liu, T., Chen, C., Qin, C., Li, X.: Int. J. Hydrogen Energy, 39, 2014, p. 18273. doi:10.1016/j.ijhydene.2014.03.041

[4] Cao, Z., Ouyang, L., Wua, Y., Wang, H., Liu, J., Fang, F., Sun, D., Zhang, Q., Zhu, M.: J. Alloy Compd., 623, 2015, p. 354. doi:10.1016/j.jallcom.2014.10.200

[5] Ismail, M.: Energy, 79, 2015, p. 177. doi:10.1016/j.energy.2014.11.001 
[6] Knotek, V., Lhotka, M., Vojtech, D.: Kovove Mater., 52, 2014, p. 345. doi:10.4149/km 20146345

[7] Lee, S. H., Park, H. R., Song, M. Y.: Korean J. Metal Mater., 53, 2015, p. 133. doi:10.3365/KJMM.2015.53.2.133

[8] Cermak, J., Kral, L., Stloukal, I.: Kovove Mater., 45, 2007, p. 305

[9] Liu, Y. N., Zou, J. X., Zeng, X. Q., Ding, W. J.: RSC Advances, 5, 2015, p. 7687. doi:10.1039/c4ra12977f

[10] Chen, Z. L., Si, T. Z., Zhang, Q. A.: J. Alloys Compd., 621, 2015, p. 42. doi:10.1016/i.jallcom.2014.09.033

[11] Ismail, M., Juahir, N., Mustafa, N. S.: J. Phys Chem. C, 118, 2014, p. 18878. doi:10.1021/jp5046436

[12] Song, M. Y., Lee, S. H., Kwak, Y. J., Park, H. R.: Korean J. Metal Mater., 52, 2014, p. 391. doi:10.3365/KJMM.2014.52.5.391

[13] Thornton, A. W., Simon, C. M., Kim, J., Kwon, O., Deeg, K. S., Konstas, K., Pas, S. J., Hill, M. R., Winkler, D. A., Haranczyk, M., Smit, B.: Chem. Mater., 29, 2017, p. 2844. doi:10.1021/acs.chemmater.6b04933

[14] Wang, Y., Wang, Y.: Prog. Net. Sci. Mater. Int., 27, 2017, p. 41. doi:10.1016/j.pnsc.2016.12.016

[15] Pistidda, C., Bergemann, N., Wurr, J., Rzeszutek, A., Møller, K. T., Hansen, B. R. S., Garroni, S., Horstmann, C., Milanese, C., Girella, A., Metz, O., Taube, K., Jensen, T. R., Thomas, D., Liermann, H. P., Klassen, T., Dornheim, M.: J. Power Sources, 270, 2014, p. 554. doi:10.1016/i.jpowsour.2014.07.129

[16] Daryani, M., Simchi, A., Sadati, M., Hosseini, H. M., Targholizadeh, H., Khakbiz, M.: Int. J. Hydrogen Energy, 39, 2014, p. 21007. doi:10.1016/j.ijhydene.2014.10.078

[17] Shang, C. X., Guo, Z. X.: J. Power Sources, 129, 2004 , p. 73. doi:10.1016/j.jpowsour.2003.11.013

[18] Zhu, Y., Liu, Z., Yang, Y., Gu, H., Li, L., Cai, M.: Int. J. Hydrogen Energy, 35, 2010, p. 6350. doi:10.1016/j.ijhydene.2010.03.094

[19] Spassov, T., Zlatanova, Z., Spassova, M., Todorova, S.: Int. J. Hydrogen Energy, 35, 2010, p. 10396 doi:10.1016/j.ijhydene.2010.07.123

[20] Imamura, H., Kusuhara, M., Minami, S., Matsumoto, M., Masanari, K., Sakata, Y., Itoh, K., Fukunaga, T.: Acta Mater., 51, 2003, p. 6407. doi:10.1016/j.actamat.2003.08.010

[21] Montone, A., Grbovic, J., Bassetti, A., Mirenghi, L., Rotolo, P., Bonetti, E., Pasquini, L., Antisari, M. V.: Materials Sci. Forum, 494, 2005, p. 137. doi:10.4028/0-87849-971-7.137

[22] Imamura, H., Tabata, S., Shigetomi, N., Takesue, Y., Sakata, Y.: J. Alloys Compd., 330-332, 2002, p. 579. doi:10.1016/S0925-8388(01)01506-7

[23] Bouaricha, S., Dodelet, P. P., Guay, D., Huot, J., Schulz, R.: J. Mater. Res., 16, 2001, p. 2893. doi:10.1557/JMR.2001.0398
[24] Pukazhselvan, D., Capurso, G., Maddalena, A., Lo Russo, S., Fagg, D. P.: Int. J. Hydrogen Energy, 39, 2014, p. 20045. doi:10.1016/j.ijhydene.2014.10.038

[25] Stoyadinova, H., Zlatanova, Z., Spassova, M., Spassov, T., Baklanov, M.: J. Nanomaterials, 2015, 2015, art. ID: 418585. doi:10.1155/2015/418585

[26] Awad, A. S., Tayeh, T., Nakhl, M., Zakhour, M., Ourane, B., Le Troëdec, M., Bobet, J.-L.: J. Alloys Compd., 607, 2014, p. 223. doi:10.1016/j.jallcom.2014.04.027

[27] Plerdsranoy, P., Javadian, P., Jensen, N. D., Nielsen, U. G., Jensen, T. R., Utke, R.: Int. J. Hydrogen Energy, 42, 2017, p. 1036. doi:10.1016/i.ijhydene.2016.09.056

[28] Gol, A. H. S., Noura, M.: Phys. Chem. Res., 5, 2017, p. 447. doi:10.22036/pcr.2017.72765.1351

[29] Jin, J., Ouyang, J., Yang, H.: Nanoscale Res. Lett., 12, 2017, p. 240. doi:10.1186/s11671-017-2000-5

[30] Elyassi, M., Rashidi, A., Hantehzadeh, M. R., Elahi, S. M.: J. Inorg. Organomet. Polym., 27, 2017, p. 285. doi:10.1007/s10904-016-0471-y

[31] Konni, M., Anima, A. S., Dadhich, S., Mukkamala, S. B.: Int. J. Hydrogen Energy, 42, 2017, p. 953. doi:10.1016/j.ijhydene.2016.09.085

[32] You, Y.-W., Moon, E.-H., Heo, I., Park, H., Hong, J.S., Suh, J.-K.: J. Indust. Eng. Chem., 45, 2017, p. 164. doi:10.1016/j.jiec.2016.09.019

[33] Zhang, C., Kong, R., Wang, X., Xu, Y., Wang, F., Ren, W., Wang, Y., Su, F., Jiang, J.-X.: Carbon, 114, 2017, p. 608. doi:10.1016/j.carbon.2016.12.064

[34] Pei, P., Whitwick, M. B., Sun, W. L., Quan, G., Cannon, M., Kjeang, E.: Nanoscale, 9, 2017, p. 4143. doi:10.1039/c6nr09545c

[35] Elyassi, M., Rashidi, A., Hantehzadeha, M. R., Elahia, S. M.: Surface and Interface Anal., 49, 2017, p. 230. doi:10.1002/sia.6122

[36] Cui, R. C., Yang, C. C., Li, M. M., Jin, B., Ding, X. D., Jiang, Q.: J. Alloys Compd., 693, 2017, p. 126. doi:10.1016/j.jallcom.2016.09.157

[37] Faye, O., Szpunar, J. A., Szpunar, B., Beye, A. C.: Appl. Surf. Sci., 392, 2017, p. 362. doi:10.1016/j.apsusc.2016.09.032

[38] Wang, C., Wu, C., Chen, S., He, Q., Liu, D., Zheng, X., Haleema, Y. A., Song, L.: RSC Advances, 7, 2017, p. 4667. doi:10.1039/c6ra25102a

[39] Yan, P., Xu, J., Zhang, X., Wu, C., Gu, Y., Zhang, R.: Int. J. Hydrogen Energy, 41, 2016, p. 14820. doi:10.1016/j.ijhydene.2016.07.045

[40] Wang, C., Wu, C., Chen, S., He, Q., Liu, D., Zheng, X. Haleem, Y. A., Song, L.: ACS Appl. Mater. Interfaces, 48, 2016, p. 33121. doi:10.1039/c6ra25102a

[41] X'Pert HighScore Plus 2.0a PANanalytical B.V., Almelo, the Netherlands. 